\title{
Behavioral problems in children with motor and intellectual disabilities: Prevalence and associations with maladaptive personality and marital relationship
}

\author{
Cis Vrijmoeth ${ }^{\mathrm{a}, \mathrm{b}}$, Elegast Monbaliu ${ }^{\mathrm{b}, \mathrm{c}}$, Emmy Lagast $^{\mathrm{b}}$, Peter Prinzie ${ }^{\mathrm{a}, \mathrm{b}, *}$ \\ ${ }^{a}$ Department of Child and Adolescent Studies, Utrecht University, The Netherlands \\ ${ }^{\mathrm{b}} \mathrm{DC} \mathrm{GID}(\mathrm{t}) \mathrm{S}$, Dominiek Savio Institute, Belgium \\ ${ }^{\mathrm{c}}$ Department of Rehabilitation Sciences, Katholieke Universiteit Leuven, Belgium
}

\section{A R T I C L E I N F O}

\section{Article history:}

Received 11 November 2011

Received in revised form 24 January 2012

Accepted 24 January 2012

Available online

\section{Keywords:}

Motor and intellectual disability

Developmental behavior checklist

Behavioral problems

Personality

Marital relationship

\begin{abstract}
A B S T R A C T
Prevalence rates of behavioral problems in children with motor disabilities are commonly based on questionnaires developed for a general population (e.g., Child Behavior CheckList). These questionnaires do not take into account lower levels of intellectual functioning. The first aim of this study was to examine the prevalence of parent-reported and daily caretaker-reported behavioral problems in children with motor and intellectual disabilities (MID) using the Developmental Behavior Checklist. Second, we investigated whether behavioral problems were related to sex and age. Our third and fourth aim were to determine whether behavioral problems are related to maladaptive personality traits and to marital stress and conflict. Participants were 101 Flemish children with MID (mean age $=14$ years 6 months). For total behavioral problems, we found prevalence rates of $18 \%$ and $8 \%$ based on parent and daily caretaker reports, respectively. Based on parent reports, twenty seven percent of the children with MID exhibited anxiety problems. Behavioral problems were not related to sex. Older children showed fewer behavioral problems than younger children. Multiple hierarchical regression analyses revealed that lower scores on Compulsivity and higher scores on Emotional Instability and Disagreeableness were related to behavioral problems. In addition to personality traits, stress and conflict in the marital relationship was also positively associated with behavioral problems. Given the importance of behavioral problems in children with MID, this study is of theoretical and clinical interest and has the potential to inform targeted clinical interventions.
\end{abstract}

(c) 2012 Elsevier Ltd. All rights reserved.

\section{Introduction}

Despite the fact that behavioral problems are often reported in children and adolescents (here referred to as children) with motor disabilities, few studies have empirically examined their prevalence (Colver, 2010). These studies reveal that prevalence estimates of behavioral problems are higher for children with motor disabilities in comparison with prevalence estimates for children in representative community samples (30\% vs. 15\%; Sniekers, Grietens, \& Maes, 2002). BrossardRacine et al. (2012) reported in a recent study a prevalence of $28 \%$ among 76 school-aged children with Cerebral Palsy. In

\footnotetext{
* Corresponding author at: Department of Child and Adolescent Studies, Utrecht University, P.O. Box 80.140, 3508 TC Utrecht, The Netherlands. Tel.: +313025345 66; fax: +31302537731.

E-mail address: p.prinzie@uu.nl (P. Prinzie).
} 
another study of preschool children with Cerebral Palsy, the parent-reported and teacher-reported prevalence estimates were even higher, 48\% and 65\%, respectively (Sigurdardottir et al., 2010). However, the use of questionnaires developed for a general population - e.g., Child Behavior Checklist (CBCL; Achenbach, 1991) and Strengths and Difficulties Questionnaire (SDQ; Goodman, 1999) - is an important limitation of most of these investigations. Delays in motor development are often accompanied by delays in cognitive development (Rosenbaum et al., 2007), which in turn often lead to a lower level of intellectual functioning. Some behavioral patterns related to lower levels of intellectual functioning (such as 'eating nonfood', 'making non-speech noises' and 'echolalia') are not included in questionnaires such as the CBCL (Einfeld \& Tonge, 1995). These questionnaires are developed for general populations in which some behaviors presume a certain level of intellectual functioning (Aman, 1991). The CBCL, for instance, is less applicable for children with a moderate, severe or profound intellectual disability (Koskentausta, Iivanainen, \& Almqvist, 2004). For this reason, the use of an instrument that covers more specific behavioral patterns, allows for a more accurate assessment of behavioral problems in children with motor and intellectual disabilities (MID). Hence, the first aim of this study was to estimate the prevalence rate of behavioral problems in children with MID. The second aim was to investigate whether parent-reported behavioral problems were related to child sex and age.

Etiological models have emphasized that risk factors within the child (such as personality) and in the proximal environment (such as marital conflicts) are associated with behavioral problems (Sameroff, 1995). However, associations among these risk factors and behavioral problems in children with MID are still understudied (Colver, 2010). During the last decade, there has been growing interest in the relationship between personality characteristics and behavioral problems (Tackett, 2006). Personality refers to individual differences in the tendency to behave, think and feel in certain consistent ways across different situations (Widiger, 2011). Scholars have reached increasing consensus on the structure by which the myriad of more specific personality traits can be arranged and the most widespread support has been obtained for the FiveFactor Model (FFM) or Big Five (Caspi \& Shiner, 2006). The Big Five dimensions have traditionally been labeled as Extraversion, Agreeableness, Conscientiousness, Neuroticism (or Emotional Instability) and Openness (Costa \& McCrae, 1992). Research has indicated that both adaptive and maladaptive personality traits are related to behavioral problems in community based populations of children and adolescents (see e.g., De Clercq, De Fruyt, Van Leeuwen, \& Mervielde, 2006; Nigg, 2006). Based on the vulnerability model, several studies have shown that personality traits are important precursors for the development of behavioral problems in children and adolescents or psychopathology in adulthood (Shiner \& Caspi, 2003; Widiger, 2011). However, to the best of our knowledge, no studies have examined the association between maladaptive personality traits and problem behavior in a sample of children with MID. Therefore, a third aim of this study was to investigate the relationship between maladaptive personality traits and behavioral problems.

An important factor in the proximal environment related to behavioral problems is stress and conflict in the marital relationship. Several studies have reported that in a normal population, higher levels of stress and conflict in the marital relationship are associated with children's behavioral problems (Amato \& Keith, 1991; Cowan \& Cowan, 2002; Jenkins, Simpson, Dunn, Rasbash, \& O'Connor, 2005). O'Leary and Vidair (2005) have shown that marital stress and conflict are related to behavioral problems through dysfunctional parenting. However, marital stress and conflict have not yet been investigated as risk factors for behavioral problems in children with MID. Hence, a fourth aim of this study was to examine the association between marital stress and conflict and behavioral problems.

\subsection{Behavioral problems}

Several studies have investigated behavioral problems in children with motor disabilities using questionnaires developed for representative community samples. Prevalence estimates vary from 21\% to 65\% (e.g., Sigurdardottir et al., 2010). This wide prevalence range may be accounted for by different psychometric characteristics of the different instruments or differences in the definition of behavior problems (e.g., use of the borderline or clinical range). Studies using the CBCL reported prevalence rates ranged from 21\% (Hendriks, De Moor, Oud, Franken, \& Savelberg, 2001), 24\% (Peters, Huisman, \& Van Emmerik-Levelt, 1999), 30\% (Sniekers et al., 2002) to 65\% (Sigurdardottir et al., 2010). Using the SDQ, prevalence rates among children with Cerebral Palsy ranged from 26\% to 40\% (Brossard-Racine et al., 2012; Parkes et al., 2008). Accordingly, the types of behavioral problems in children with motor disabilities also varied. The most reported problems are anxiety (Hendriks et al., 2001; Van Handel, Swaab, De Vries, \& Jongmans, 2010), attention problems (Peters et al., 1999; Sigurdardottir et al., 2010), social problems (Hinton, Nereo, Fee, \& Cyrulnik, 2006) and hyperactivity (Brossard-Racine et al., 2012; McDermott et al., 1996; Parkes et al., 2008). However, the use of different questionnaires hampers the comparability of studies addressing the prevalence of different types of problem behavior. Therefore, our first aim was to estimate parentreported and daily caretaker-reported prevalence rates of behavioral problems in children with MID using the Dutch translation (Koot \& Dekker, 2001) of the Developmental Behavior Checklist (DBC; Einfeld \& Tonge, 1992). This instrument is developed for children with intellectual disabilities.

Past research in behavioral problems of children with motor disabilities relied largely on parent reports (e.g., BrossardRacine et al., 2012; Parkes et al., 2008) and to a lesser extent on teacher reports (e.g., Sigurdardottir et al., 2010). Communitybased studies have revealed that parents report higher prevalence rates of behavioral problems than teachers (e.g., Grietens et al., 2004). However, Sigurdardottir et al. (2010) found that teachers reported higher prevalence rate of behavior problems for children with Cerebral Palsy. In this study, we extended past research by including daily caretakers, in addition to parents, as informants. Several authors have recommended a multiple informant approach because different informants add 
different but legitimate and unique information about child functioning (Bartels et al., 2003; Grietens et al., 2004). Informants differ not only in the way they interpret behavior but also in the type of interactions they have with children. An important advantage of the inclusion of daily caretakers is that they are familiar with a broader range of children and they have greater expertise regarding normal and abnormal child development than parents (Grietens et al., 2004; Saudino, Ronald, \& Plomin, 2005). Furthermore, daily caretakers are valuable informants because some behavioral problems are primarily exhibited in interactions with other children and daily caretakers are more likely to see these interactions. Hence, we investigated both the parent-reported and daily caretaker-reported prevalence rates of behavioral problems in children with MID.

\subsection{Risk factors of behavioral problems within the child}

\subsubsection{Sex and age}

With regard to risk factors within the child, previous research has reported mixed results about the associations between behavioral problems and sex or age. For example, some studies found that boys exhibited more behavioral problems than girls (e.g., Sniekers et al., 2002), whereas others (e.g., Sipal, Schuengel, Voorman, Van Eck, \& Becher, 2010) found no differences between boys and girls. With regard to age, Sipal et al. (2010) reported lower prevalence estimates for older children with Cerebral Palsy. In contrast, other investigations revealed that age was not related to behavioral problems (e.g., Parkes et al., 2008). Because of these inconsistencies in the literature, the second aim was to investigate whether behavioral problems in children with MID are related to sex and age.

\subsubsection{Maladaptive personality traits}

There is growing consensus that the FFM is best suited to capture adaptive or normal differences in personality (Clercq, De Fruyt, \& Widiger, 2009). From a dimensional perspective, it is suggested that personality traits can be described along a continuum (De Clercq, De Fruyt, Van Leeuwen, \& Mervielde, 2006; Widiger, 2011). In this perspective personality disorders and maladaptive personality traits are seen as extreme variants of normal personality traits (Widiger \& Mullins-Sweatt, 2009). In addition, there is a growing agreement that both adaptive and maladaptive personality traits can be measured from early childhood on (Shiner \& Caspi, 2003; De Clercq, De Fruyt, \& Widiger, 2009). The importance of a dimensional classification of personality is emphasized by work groups preparing the future Diagnostic and Statistical Manual of Mental Disorders-Fifth edition (DSM-V) (Widiger \& Mullins-Sweatt, 2009). In line with the dimensional perspective, De Clercq, De Fruyt, and Mervielde (2003) developed the Dimensional Personality Symptom Item Pool (DIPSI), a four-factor maladaptive personality questionnaire for children and adolescents. This questionnaire measures Introversion, Disagreeableness, Compulsivity and Emotional Instability. A maladaptive trait variant of Openness was not developed because this factor is generally not included in measures for adult personality pathology (see De Clercq et al., 2006, p. 4).

One theoretical model proposed for the study between personality and behavioral problems is the vulnerability model (see e.g., Nigg, 2006; Tackett, 2006). According to this model, maladaptive personality traits are hypothesized as predisposing factors for the onset of behavioral problems (De Clercq et al., 2009; Widiger, 2011). However, previous research has mainly focused on the associations between behavioral problems and measures of adaptive personality traits. For example, research in representative community samples has identified consistent relationships between low Conscientiousness, low Agreeableness, high Extraversion and to a lesser extent high Neuroticism (Prinzie et al., 2003; Prinzie, Van der Sluis, De Haan, \& Deković, 2010; Tackett, 2006; Van Leeuwen, Mervielde, Braet, \& Bosmans, 2004) and behavioral problems. Given the importance of personality in the forthcoming DSM-V (Widiger, 2011; Widiger \& Mullins-Sweatt, 2009) and the fact that maladaptive personality traits have not yet been studied in children with MID, the third aim of this study was to investigate the association of behavioral problems with maladaptive personality traits.

\subsection{Environmental risk factors of behavioral problems}

An important risk factor in the proximal environment of the child that has been related to behavioral problems is conflict in the marital relationship (e.g., Cowan \& Cowan, 2002). The family conflict perspective states that children's adjustment and well-being is negatively influenced by higher levels of interparental conflict and stress (Amato \& Keith, 1991). According to Jenkins et al. (2005) and Cowan and Cowan (2002) interparental conflicts are related to behavioral problems. In particular, stress and conflict regarding child rearing practices have shown to be important risk factors for behavioral problems in children (Jenkins et al., 2005; O'Leary \& Vidair, 2005). Therefore, the fourth aim of this study was to investigate whether behavioral problems were related to stress and conflict in the marital relationship.

\subsection{This study}

In summary, the first aim of this study was to estimate prevalence rates of behavioral problems in children with MID using the DBC. Because this study is the first to use the DBC in children with MID, analyses regarding prevalence rates were exploratory. Based on the literature on prevalence rates in representative community samples (Grietens et al., 2004), we hypothesized that parents would report more behavioral problems than daily caretakers. Second, we aimed to investigate the associations of behavioral problems with sex and age. Given inconsistencies in the literature, analyses with regard to sex 
and age were also exploratory. A third aim was to examine of the association between behavioral problems and maladaptive personality traits. Based on the literature on personality traits in normal populations and in line with the vulnerability model, we hypothesized that low scores on Compulsivity, high scores on Emotional Instability and high scores on Disagreeableness would be related to behavioral problems (Prinzie et al., 2003, 2010; Tackett, 2006; Van Leeuwen et al., 2004). Fourth, we aimed to investigate the relationship between behavioral problems and marital stress and conflict. From the family conflict perspective (Amato \& Keith, 1991), we hypothesized that in addition to maladaptive personality, higher scores on stress and conflict in the marital relationship would be associated with more behavioral problems (e.g., Cowan \& Cowan, 2002; Jenkins et al., 2005).

\section{Materials and methods}

\subsection{Participants}

Participants were recruited in the Dominiek Savio Institute, a service center in Belgium for children and adolescents with physical or multiple disabilities. The institute offers ambulatory, semi-residential, and residential services to children and adults who need support in the domains of living, education, and work. The sample consisted of children with MID who were taught in the institute. A total of 101 children participated in the study (71\% of those eligible). Children who met the following criteria were included: (1) age between six and twenty-one years and (2) intelligence functioning comparable to an intellectual disability (IQ score below 85). The mean age of the participants was 14.50 years (SD = 4.21). Other background characteristics of the participants are presented in Table 1. Gross motor function as classified by the Gross Motor Function Classification System (GMFCS; Palisano et al., 1997) is shown for the children with Cerebral Palsy. This study included a representative group of children with MID (e.g., Cerebral Palsy, Spina Bifida) and all levels of gross motor function were represented (see Table 1). Because no differences in behavioral problems between children with different types of motor disabilities were found, type of motor disability was not included in further analyses. Missing values in parent reports were missing completely at random (Little's MCAR test: $\left.\chi^{2}(6, N=101)=4.49, p=.94\right)$. Therefore, to maximize sample size, missing values were imputed with the Expected-Maximization (EM) algorithm as recommended by Schafer and Graham (2002).

\subsection{Procedure}

Parents and daily caretakers of the Dominiek Savio Institute were asked to complete the DBC (Koot \& Dekker, 2001). In most cases the mother participated (81\%). Parents also completed the subscale spouse of the Parenting Stress Index (PSI;

Table 1

Background characteristics of the participating children $(N=101)$.

\begin{tabular}{|c|c|c|}
\hline & $N$ & $\%$ \\
\hline \multicolumn{3}{|l|}{ Sex } \\
\hline Boys & 63 & 62 \\
\hline Girls & 38 & 38 \\
\hline \multicolumn{3}{|l|}{ Level of education } \\
\hline Primary school & 36 & 36 \\
\hline Secondary school & 65 & 64 \\
\hline \multicolumn{3}{|l|}{ Motor disability } \\
\hline Cerebral Palsy & 45 & 44 \\
\hline Spina Bifida & 8 & 8 \\
\hline Degenerative disease (e.g., Duchenne muscular disease) & 12 & 12 \\
\hline Traumatic brain injury & 10 & 10 \\
\hline Syndromic (e.g., Steinert disease) & 16 & 16 \\
\hline Other or not yet diagnosed conditions & 10 & 10 \\
\hline \multicolumn{3}{|l|}{ Gross motor function ${ }^{\mathrm{a}}$} \\
\hline GMFCS Level I & 8 & 18 \\
\hline GMFCS Level II & 12 & 27 \\
\hline GMFCS Level III & 6 & 13 \\
\hline GMFCS Level IV & 6 & 13 \\
\hline GMFCS Level V & 13 & 29 \\
\hline \multicolumn{3}{|l|}{ Intellectual disability } \\
\hline Borderline intellectual disability (IQ 70-84) & 27 & 27 \\
\hline Mild intellectual disability (IQ 50-69) & 51 & 50 \\
\hline Moderate intellectual disability (IQ 35-49) & 19 & 19 \\
\hline Severe intellectual disability (IQ 20-34) & 4 & 4 \\
\hline \multicolumn{3}{|l|}{ Additional disability } \\
\hline Visual impairment & 54 & 54 \\
\hline Hearing impairment & 3 & 3 \\
\hline Communication impairment & 44 & 44 \\
\hline Seizures & 6 & 6 \\
\hline
\end{tabular}

a Only for children with Cerebral Palsy $(N=45)$. 
Abidin, 1990). Finally, to measure maladaptive personality traits, daily caretakers rated the DIPSI (De Clercq et al., 2003). In this study, daily caretakers had experience with the children for at least six months. Prior to the data collection; both informants signed informed consent. Background characteristics of all participants were found in case files.

\subsection{Measures}

\subsubsection{Behavioral problems}

The DBC was used to measure behavioral problems (Koot \& Dekker, 2001). This questionnaire was developed and validated in Australia by Einfeld and Tonge (1995). The DBC contains 95-items measuring five subscales: (1) disruptive/ antisocial behavior (27 items: e.g., temper tantrums; irritable; steals), (2) self-absorbed behavior (31 items: e.g., eats nonfood items; chews or mouths objects or body parts), (3) communication disturbance (13 items: e.g., echolalia; talks to oneself), (4) anxiety (9 items: e.g., excessively distressed when separated; distressed about being alone), and (5) social relating problems (19 items: e.g., doesn't show affection; aloof, in his/her own world). Each item is scored on a three point Likert scale, where $0=$ not true, $1=$ somewhat or sometimes true, $2=$ highly or often true. These responses were based on observations during the last six months. The DBC is a valid and reliable instrument for the measurement of behavioral problems in children and adolescents with intellectual disabilities (Dekker, Nunn, \& Koot, 2002; Einfeld \& Tonge, 1995; Koskentausta \& Almqvist, 2004). Cronbach's alphas for the Total Problems scale were high for parent reports $(\alpha=.96)$ and for daily caretaker reports $(\alpha=.95)$. The Cronbach's alphas coefficients for the subscales ranged from .66 for anxiety (daily caretaker reports) and .71 for social relating problems (parent reports) to .90 for self-absorbed behavior (parent reports) and .92 for disruptive/antisocial behavior (daily caretakers).

\subsubsection{Maladaptive personality traits}

The DIPSI (De Clercq et al., 2003) was used to measure the maladaptive personality traits. This questionnaire contains 172 items, ordered in 27 subscales, which refer to maladaptive personality traits in children in and adolescents. The items and the subscales are hierarchically organized into four higher level factors: (1) Disagreeableness (86 items: e.g., often loses one's self-control, constantly disobeys the rules, feels none compassion when somebody is hurt), (2) Emotional Instability (52 items: e.g., panics very easily, is very sensitive to stress, often feels empty inside), (3) Introversion (19 items: e.g., fears every contact with other children, always hides one's feelings) and (4) Compulsivity (15 items: e.g., wants life to be perfectly organized, is obsessed by cleaning). De Clercq et al. (2006) have empirically shown that these four factors conceptually correspond with the structure of questionnaires that measure maladaptive personality traits in adults, suggesting that precursors of personality disorders can be measured in childhood and adolescence. Items are rated on a five point Likert scale ranging from 1 (barely characteristic) to 5 (highly characteristic). Cronbach's alphas showed high internal consistencies for Introversion $(\alpha=.90)$, Compulsivity $(\alpha=.92)$, Emotional Instability $(\alpha=.97)$ and Disagreeableness $(\alpha=.98)$.

\subsubsection{Stress and conflict in the marital relationship}

To measure stress and conflict in the marital relationship, parents completed the Spouse scale of the PSI (Abidin, 1990; Jones \& Prinz, 2005). This scale consists of 7 items and measures stress and conflicts related to (1) absence of support by the partner ('Since the birth of this child my partner gives less support than I had expected'), (2) child management strategies ('Lately, my partner and I have some disagreement about the approach of our child'), and (3) loss of sharing ('Since the birth of this child my partner and I don't spend much time together anymore'). Items are rated on a six point Likert scale ranging from 1 (disagree completely) to 6 (agree completely). The Cronbach's alpha coefficient was .85 .

\subsection{Data analyses}

To answer our first aim, the estimation of prevalence rates of behavioral problems in children with MID, we used the combined percentile scores of the Dutch normative sample of trainable (IQ 30-60) and educable (IQ 60-80) children in non-residential school settings (for a more detailed description, see Dekker et al., 2002). As described by Koot and Dekker (2001), we dichotomized the scores on the DBC scales into scores in the deviant or clinical range $(\geq 75)$ and scores in the normal range $(<75)$. To test whether prevalence rates of parents and daily caretakers differed significantly, we used McNemar's test of symmetry. For our second aim, we performed $T$-tests to investigate the association between sex and parent-reported behavioral problems. Pearson's correlations were computed to investigate whether parent-reported behavioral problems were related to child age. For our third and fourth aim, the associations of parent-reported behavioral problems with daily caretaker-reported maladaptive personality traits and with parental reported stress and conflict in the marital relationship, we performed a multiple hierarchical regression model for each subscale of the DBC. In the first step, we controlled for age and sex. Disagreeableness, Emotional Instability, Introversion and Compulsivity as reported by daily caretakers were included in the second step. In the final step, the parent-reported stress and conflict in the marital relationship was added to the regression models. The inclusion of daily caretaker reports allowed to avoid rater bias as an explanation for the associations between behavioral problems and maladaptive personality traits (Hawker \& Boulton, 2000). 


\section{Results}

\subsection{Behavioral problems}

\subsubsection{Descriptive statistics}

Table 2 presents the mean scores and standard deviations for parent-reported and daily caretaker-reported behavioral problems. T-tests revealed that the mean scores of parent reports were significantly higher than the mean scores of daily caretaker reports on total problems $(t(100)=2.79, p<.01)$, self-absorbed behavior $(t(100)=3.02, p<.01)$, communication disturbance $(t(100)=2.43, p<.01)$ and anxiety $(t(100)=3.02, p<.01)$. Correlations between parent-reported and daily caretaker-reported behavioral problems ranged from .13 $(p=.19)$ for social relating problems to $.52(p<.01)$ for selfabsorbed behavior. For the score on total problems, the correlation was moderate $(r=.32, p<.01)$.

\subsubsection{Prevalence rates}

Prevalence rates of children with a deviant or clinical score are presented in Table 3. Prevalence rates were higher in parent reports than in daily caretaker reports for the total problems scale $\left(\chi^{2}(1, N=101)=2.30, p<.05\right)$ and anxiety scale $\left(\chi^{2}(1, N=101)=1.58, p<.05\right)$. According to parents, $18 \%$ of the children had a deviant/clinical total score, compared to $8 \%$ in daily caretaker reports. Anxiety was by far the most reported problem by parents (27\%), followed by communication disturbance (20\%), self-absorbed behavior (18\%), social relating problems (18\%) and disruptive/antisocial behavior ( $8 \%$ ). Based on daily caretaker-reports, the prevalence rates were: communication disturbance (16\%), anxiety (15\%), social relating problems (15\%), self-absorbed behavior (10\%) and disruptive/antisocial behavior (9\%).

\subsection{Sex and age}

$T$-tests were performed to investigate gender differences in problem behavior. As can be seen in Table 4, parent-reported mean scores were not significantly different for boys and girls. To investigate whether age was related to problem behavior, Pearson correlations were computed. As can be seen in Table 5, age was negatively related to self-absorbed behavior $(r(99)=-.28, p<.01)$, communication disturbance $(r(99)=-.28, p<.01)$ and anxiety $(r(99)=-.30, p<.01)$ indicating that older children exhibited fewer behavioral problems.

\subsection{Maladaptive personality traits}

Correlations between daily caretaker-reported personality and parent-reported behavioral problems are presented in Table 5. Disagreeableness was positively related to disruptive/antisocial behavior and self-absorbed behavior. To investigate

Table 2

Mean scores and standard deviations of behavioral problems.

\begin{tabular}{|c|c|c|c|c|}
\hline \multirow[t]{2}{*}{ DBC scale } & \multirow{2}{*}{$\frac{\text { Parents }}{\text { Mean (SD) }}$} & \multirow{2}{*}{$\begin{array}{l}\text { Daily caretakers } \\
\text { Mean (SD) }\end{array}$} & \multicolumn{2}{|c|}{ Parents vs. daily caretakers } \\
\hline & & & $t$ & Cohen's $d$ \\
\hline Disruptive/antisocial behavior & $.33(.25)$ & $.30(.28)$ & .92 & .10 \\
\hline Self-absorbed behavior & $.21(.21)$ & $.15(.17)$ & $3.02^{* *}$ & .30 \\
\hline Communication disturbance & $.30(.30)$ & $.22(.25)$ & $2.43^{*}$ & .30 \\
\hline Anxiety & $.38(.34)$ & $.27(.25)$ & $3.02^{* *}$ & .37 \\
\hline Social relating Problems & $.25(.37)$ & $.19(.22)$ & 1.76 & .23 \\
\hline Total problems & $.28(.21)$ & $.21(.18)$ & $2.79^{* *}$ & .33 \\
\hline
\end{tabular}

${ }^{*} p<.05$.

** $p<.01$.

Table 3

Parent-reported and daily caretaker-reported prevalence rates of behavioral problems.

\begin{tabular}{|c|c|c|c|}
\hline \multirow[t]{2}{*}{ DBC scale } & Parents & Daily caretakers & Parents vs. daily caretakers \\
\hline & $\%$ & $\% \mathrm{a}$ & $\chi^{2 b}$ \\
\hline Disruptive/antisocial behavior & 8 & 9 & .14 \\
\hline Self-absorbed behavior & 18 & 10 & 13.48 \\
\hline Communication disturbance & 20 & 16 & .32 \\
\hline Anxiety & 27 & 15 & $1.58^{*}$ \\
\hline Social relating problems & 18 & 15 & .24 \\
\hline Total problems & 18 & 8 & $2.30^{*}$ \\
\hline
\end{tabular}

a $>75$ th percentile cut-off score.

b Significant in McNemar's test of symmetry

* $p<.05$. 
Table 4

Mean scores and standard deviations of parent-reported behavioral problems for boys and girls.

\begin{tabular}{|c|c|c|c|}
\hline \multirow[t]{2}{*}{ DBC scale } & Boys $(N=63)$ & Girls $(N=38)$ & Boys vs. girls \\
\hline & Mean (SD) & Mean $(S D)$ & $t$ \\
\hline Disruptive/antisocial behavior & $.34(.26)$ & $.31(.23)$ & .63 \\
\hline Self-absorbed behavior & $.23(.23)$ & $.18(.18)$ & .95 \\
\hline Communication disturbance & $.32(.31)$ & $.27(.28)$ & .82 \\
\hline Anxiety & $.36(.33)$ & $.41(.35)$ & -.80 \\
\hline Social relating problems & $.26(.27)$ & $.22(.26)$ & .73 \\
\hline Total problems & $.29(.21)$ & $.26(.20)$ & .59 \\
\hline
\end{tabular}

Table 5

Pearson correlations between age, daily caretaker-reported maladaptive personality, marital relationship and parent-reported behavioral problems.

\begin{tabular}{|c|c|c|c|c|c|c|c|c|c|c|c|}
\hline & 1 & 2 & 3 & 4 & 5 & 6 & 7 & 8 & 9 & 10 & 11 \\
\hline \multicolumn{12}{|l|}{ 1. Age $^{\mathrm{a}}$} \\
\hline \multicolumn{12}{|l|}{ Personality } \\
\hline 2. Disagreeableness & .07 & & & & & & & & & & \\
\hline 3. Emotional Instability & .14 & $.75^{* * *}$ & & & & & & & & & \\
\hline 4. Introversion & .05 & $.61^{* * *}$ & $.76^{* * *}$ & & & & & & & & \\
\hline 5. Compulsivity & .09 & $.52^{* * *}$ & $.66^{* * *}$ & $.53^{* * *}$ & & & & & & & \\
\hline \multicolumn{12}{|l|}{ Parenting stress } \\
\hline 6. Marital relationship & .00 & .10 & .03 & .00 & -.09 & & & & & & \\
\hline \multicolumn{12}{|l|}{ Behavioral problems } \\
\hline 7. Disruptive/antisocial behavior & -.17 & $.31^{* *}$ & .10 & .02 & -.11 & $.38^{* * *}$ & & & & & \\
\hline 8. Self-absorbed behavior & $-.28^{* *}$ & $.25^{*}$ & .18 & .06 & -.11 & $.27^{* *}$ & $.68^{* * *}$ & & & & \\
\hline 9. Communication disturbance & $-.28^{* *}$ & .07 & .11 & .04 & -.09 & $.21^{*}$ & $.62^{* * *}$ & $.83^{* * *}$ & & & \\
\hline 10. Anxiety & $-.30^{* *}$ & .06 & .08 & .05 & .03 & $.26^{* *}$ & $.49^{* * *}$ & $.47^{* * *}$ & $.62^{* * *}$ & & \\
\hline 11. Social relating problems & -.03 & .05 & .06 & .07 & -.15 & $.28^{* *}$ & $.55^{* * *}$ & $.55^{* * *}$ & $.64^{* * *}$ & $.42^{* * *}$ & \\
\hline $\begin{array}{l}\text { a Age in years. } \\
{ }^{*} p<.05 . \\
{ }^{*} p<.01 \\
{ }^{* *} \quad p<.001 .\end{array}$ & & & & & & & & & & & \\
\hline
\end{tabular}

whether maladaptive personality traits and marital stress can predict behavioral problems, separate multiple hierarchical regressions were performed. The results of these analyses are presented in Table 6 . In the first step, we controlled for sex and age. As can be seen in Table 6 , for disruptive/antisocial behavior a significant effect was found Disagreeableness $(\beta=.49$, $p<.01)$ and Compulsivity $(\beta=-.27, p<.05)$. For self-absorbed behavior, a significant effect was found for Emotional Instability $(\beta=.47, p<.01)$ and for Compulsivity $(\beta=-.38, p<.01)$. For communication disturbance, a statistically significant effect was found for Emotional Instability $(\beta=.46, p<.05)$ and for Compulsivity $(\beta=-.26, p<.05)$. Social relation problems were predicted by Compulsivity $(\beta=-.30, p<.01)$. Anxiety was not predicted by any of the maladaptive personality traits.

\subsection{Stress and conflict in the marital relationship}

To investigate the predictive power of stress and conflict in the marital relationship, this variable was added to the regression model in the last step (Table 6). As can be seen in Table 6, stress and conflict in the marital relationship predicted higher scores on parent-reported disruptive/antisocial behavior $(\beta=.30, p<.05)$, self-absorbed behavior $(\beta=.20, p<.05)$, anxiety $(\beta=.26, p<.05)$ and social relating problems $(\beta=.26, p<.05)$. Only communication disturbance was not associated with marital stress and conflict. The final models explained $14 \%$ of the variance for social relating problems to $33 \%$ for disruptive/antisocial behavior.

\section{Discussion}

This study aimed to estimate prevalence rates for behavioral problems in children with motor and intellectual disabilities (MID) and to investigate to what extent risk factors within the child (sex, age and maladaptive personality traits) and within the proximal environment (marital conflict) are related to behavior problems. The use of the DBC, a questionnaire that covers behavioral patterns related to lower levels of intellectual functioning, is an important contribution of this study and allows for more accurate prevalence estimates. Moreover, this study is one of the first to investigate the relationship between maladaptive personality traits and behavioral problems in a sample of children with MID. Furthermore, to the best of our knowledge, only a few studies included stress and conflict in the marital relationship as risk factors for behavioral problems in children with disabilities. 
Table 6

Age, sex, maladaptive personality traits and marital relationship as predictors of parent-reported behavioral problems.

\begin{tabular}{|c|c|c|c|c|c|c|c|c|c|c|c|c|c|c|c|c|c|c|c|c|}
\hline \multirow[t]{2}{*}{ Predictor } & \multicolumn{4}{|c|}{ Disruptive/Antisocial Behavior } & \multicolumn{4}{|c|}{ Self-absorbed Behavior } & \multicolumn{4}{|c|}{ Communication Disturbance } & \multicolumn{4}{|c|}{ Anxiety } & \multicolumn{4}{|c|}{ Social Relating Problems } \\
\hline & $\Delta F$ & $B$ & SE B & $\beta$ & $\Delta F$ & $B$ & SE B & $\beta$ & $\Delta F$ & $B$ & SE B & $\beta$ & $\Delta F$ & $B$ & SE B & $\beta$ & $\Delta F$ & $B$ & SE B & $\beta$ \\
\hline Age & 1.49 & -.01 & .01 & -.17 & $4.35^{*}$ & -.02 & .00 & $-.31^{* *}$ & $4.51^{*}$ & -.02 & .01 & $-.31^{* *}$ & $5.50^{* *}$ & -.03 & .01 & $-.33^{* *}$ & .29 & .00 & .01 & -.03 \\
\hline Sex & & -.02 & .04 & -.05 & & -.04 & .04 & .09 & & -.06 & .06 & -.09 & & .06 & .07 & .09 & & -.06 & .05 & -.10 \\
\hline Disagreeableness & $6.41^{* *}$ & .23 & .06 & $.49^{* *}$ & $6.44^{* *}$ & .09 & .05 & .23 & 2.27 & -.04 & .08 & -.07 & .55 & -.04 & .09 & -.06 & 1.82 & -.03 & .07 & -.06 \\
\hline Emotional Instability & & .02 & .07 & .05 & & .15 & .06 & $.47^{* *}$ & & .21 & .09 & $.46^{*}$ & & .11 & .10 & .21 & & .10 & .08 & .24 \\
\hline Introversion & & -.09 & .07 & -.16 & & -.11 & .06 & -.22 & & -.09 & .10 & -.13 & & -.05 & .11 & -.07 & & .04 & .09 & .07 \\
\hline Compulsivity & & -.11 & .05 & $-.27^{*}$ & & -.14 & .04 & $-.38^{* *}$ & & -.13 & .06 & $-.26^{*}$ & & .01 & .07 & .02 & & -.13 & .06 & $-.30^{*}$ \\
\hline Marital relationship & $12.32^{* *}$ & .06 & .02 & $.30^{* *}$ & $5.27^{*}$ & .04 & .02 & $.20^{*}$ & 3.76 & .05 & .02 & .18 & $7.17^{* *}$ & .07 & .03 & $.26^{* *}$ & $6.84^{*}$ & .06 & .02 & $.26^{*}$ \\
\hline
\end{tabular}

Marital relationship

$.04 \quad .02$

3.76

Note: Final mod.
${ }^{*} p<.05$.

** $p<.01$. 


\subsection{Behavioral problems}

With regard to our first aim, the prevalence of behavioral problems, results indicate a relatively high prevalence of parentreported behavioral problems in children with MID. According to parents, $18 \%$ of the children had a deviant or clinical score on the total problems score, whereas daily caretakers reported a prevalence of $8 \%$. For the subscales, prevalence rates were even higher. We found parent-reported prevalence rates of $27 \%$ for anxiety, followed by $20 \%$ for communication disturbance. Daily caretaker-reported prevalence rates were highest for communication disturbance (16\%) and for anxiety (15\%).

For anxiety, the parent-reported prevalence was significantly higher than daily caretaker-reported prevalence. A possible explanation for the difference between raters is that parents of a child with a disability view their child as dependent and in need of help and protection (Woolfson, 2004). This may result in overcontrolling and overprotective parenting which may evoke anxiety in children (Van Bruggen, Stams, \& Bögels, 2008). On the other hand, parents (especially mothers) usually have more contact with their child and are therefore more aware of internalizing problems, such as anxiety. The higher prevalence of parent-reported anxiety may be due to the better visibility for parents and the overprotective parenting (Grietens et al., 2004). Taken together, the prevalence rates indicate that anxiety is an important domain in which children with MID can develop problems.

For the total problems score, the parent-reported prevalence was also significantly higher than daily caretaker-reported prevalence. This finding is congruent with the significantly higher parent-reported levels of total behavioral problems. Other studies also reported the tendency of parents, particularly mothers, to report more behavioral problems than professional workers (Grietens et al., 2004). These differences may reflect true variability in the child's behavior in different settings or variability in the informant's perceptions, due to the knowledge of (ab)normal child development or different expectations regarding children's behavior. Woolfson (2004) integrated the parental expectations into a model that aimed to explain disability-related behavioral problems. According to this model, parental attitudes and beliefs about their child's disability may influence their parenting (Woolfson, 2004). Parents may experience more difficulties in managing behavioral problems and setting boundaries for appropriate behavior when they view behavioral problems as inevitable and unchangeable parts of the child's disability caused by a medical problem. This may also be the case when the disability is viewed as a tragedy for the child. Parents may be reluctant to discipline their children because of the child's disability and this may lead to more behavioral problems (Woolfson, 2004). In line with Colver (2010), we suggest that clinicians should focus on supporting parents in managing the child with a motor disability the same way as they manage their other children, because behavioral problems often are the result of interactions between parents and children and not the result of the child's disability.

\subsection{Sex and age}

Our second aim was to investigate associations of sex and age with behavioral problems. Findings indicate that boys and girls did not exhibit different levels or different types of behavioral problems. Results indicated that older children with MID had fewer behavioral problems, in particular less self-absorbed behavior, communication disturbance and anxiety. The results with regard to sex and age are in accordance with longitudinal results of Sipal et al. (2010). The results about age are also found in other populations. For example, a study in a large sample of a general population (Bongers, Koot, Van der Ende, \& Verhulst, 2003) and a study in a large sample of children with intellectual disabilities (De Ruiter, Dekker, Verhulst, \& Koot, 2007) both reported a decrease in behavioral problems over time. One possible explanation is that that during the transition from childhood into adolescence children with MID disclose less of their feelings and thoughts to their parents, spend more time with their friends and less time with their parents. Hence, behavioral problems may be less visible for parents during adolescence.

\subsection{Maladaptive personality traits}

With regard to our third aim, regression analyses revealed that maladaptive personality traits were significantly related to behavioral problems. Lower scores on Compulsivity were significantly related to higher scores on four out of five behavioral problem scales (disruptive/antisocial behavior, self-absorbed behavior, communication disturbance and social relating problems). In line with our hypothesis, higher scores on Emotional Instability were related to more self-absorbed behavior and communication disturbance. Further, higher scores on Disagreeableness were related to more disruptive/ antisocial behavior. Results showed no association of maladaptive personality traits with anxiety. Taken together, results in children with MID are similar to results of studies in a normal population in that lower scores on Compulsivity (Prinzie et al., 2003; Van Leeuwen et al., 2004), higher scores on Emotional Instability (Tackett, 2006) and Disagreeableness (Prinzie et al., 2010) are risk factors for developing behavioral problems, supporting the vulnerability model. These maladaptive personality traits may function as a diathesis by predisposing a child with MID for developing behavioral problems under specific circumstances. One mechanism that has been put forward is the effect of the interaction between personality traits and parenting on the development of behavioral problems (e.g., Prinzie et al., 2003, 2010). These interactions may reflect an evocative transactional process between the child and the parents (Roberts \& Caspi, 2003). Children who score high on Disagreeableness may evoke more negative parenting which may result in more behavior problems. Therefore, in clinical interventions it is essential to build upon a goodness-of-fit between the child's personality and child management strategies (Prinzie et al., 2003). For example, excessive or negative discipline may evoke antisocial behavior in a child characterized by 
high levels of Disagreeableness instead of reducing antisocial behavior. Furthermore, helping parents develop and maintain effective behavior management techniques, and specifically, teaching them to implement management techniques in a way that complements the child's personality characteristics may be particularly effective for interventions.

\subsection{Stress and conflict in the marital relationship}

Our fourth aim was to investigate associations of stress and conflict in the marital relationship with behavioral problems. We found that higher levels of marital stress and conflict were associated with higher levels of behavioral problems. This result supports the family conflict model stating that children show more behavioral problems in families characterized with higher levels of marital conflict and stress. A possible mechanism is that marital conflict and stress make parents less capable in nurturing and raising children (Amato \& Keith, 1991) and in managing behavioral problems (Cowan \& Cowan, 2002; O'Leary \& Vidair, 2005). In general, children with disabilities need more care than typically developing children (Raina et al., 2005) and are susceptible to changes in the proximal environment and changes regarding closely related persons. For these reasons, children with MID may be extra sensitive to stress and conflict in the marital relationship. The importance of stress related to the marital relationship is also emphasized by Mitchell and Hauser-Cram (2009), who showed that a better relationship between family members was a significant contributor to lower levels of behavioral problems in children with developmental disabilities. Therefore, clinicians should focus on supporting parents in managing stress and conflict in the marital relationship in order to reduce the probability of behavioral problems (Amato \& Keith, 1991; Cowan \& Cowan, 2002; Sipal et al., 2010).

\subsection{Limitations and future research}

Although this study added several new insights to the study of the prevalence of and risk factors for behavioral problems in children with MID, we have to mention several limitations. First of all, we used a cross-sectional design which makes it impossible to investigate causal relations. Although we found clear associations of behavioral problems with stress and conflict in the marital relationship, it is not clear whether behavioral problems in a child are the outcome of the marital relationship as a stressor or vice versa (see e.g., Ketelaar, Volman, Gorter, \& Vermeer, 2008). The focus of future longitudinal research should be on predicting changes in behavioral problems by (changes in) the levels of marital stress and conflict. Second, given the large sample size, we used only questionnaires for parent and daily caretaker reports. Further research may enhance the accuracy of our results by including multiple method measurements, such as observational methods. Third, because we used only the higher level factors of maladaptive personality traits (e.g., Disagreeableness) future research should also investigate the relation between the lower level facets and behavioral problems.

\subsection{Conclusions}

Taken together, this study is of theoretical and clinical interest because it demonstrates (1) the high prevalence of behavioral problems in children with MID and (2) the importance of maladaptive personality traits and marital stress and conflict as risk factors for behavioral problems. The use of the DBC extends previous studies and allowed for a different and more accurate assessment of behavioral problems in children with MID. The present study also extends previous studies by focusing on the child's personality and marital stress and conflict as risk factors of behavioral problems. The findings in this study favor a family-centered approach of targeted clinical interventions of behavioral problems in children with MID. Clinicians should in particular focus on (1) supporting parents in managing the child with a motor disability the same way as they manage their other children, (2) supporting parents in adopting adequate child management strategies congruent with the personality of the child, and (3) supporting parents in managing stress and conflict in the marital relationship.

\section{Role of the funding source}

This work was partly supported by a grant of the Marguerite-Marie Delacroix Foundation.

\section{Acknowledgements}

The authors would like to thank Dr. Gerald van Gurp (Faculty of Medicine, McGill University, Canada) and Susan van Gurp (PhD, Principal, B.C. School for the Deaf, Canada) for their thoughtful comments and remarks to this article. Very special thanks must go to the participating children, parents and daily caretakers of the Dominiek Savio Institute.

\section{References}

Abidin, R. R. (1990). Introduction to the special issue: The stresses of parenting. Journal of Clinical Child Psychology, 19, $298-301$.

Achenbach, T. M. (1991). Manual for the CBCL/4-18 and 1991 profile. Burlington: University of Vermont, Department of Psychiatry.

Aman, M. G. (1991). Review and evaluation of instruments for assessing emotional and behavioral disorders. Australian and New Zealand Journal of Developmental Disorders, 17, 127-145.

Amato, P. R., \& Keith, B. (1991). Parental divorce and the well-being of children: A meta-analysis. Psychological Bulletin, 110, $26-46$. 
Bartels, M., Hudziak, J. J., Boomsma, D. I., Rietveld, M. J. H., Van Beijsterveldt, T. C. E. M. , \& Van den Oord, E. J. C. G. (2003). A study of parent ratings of internalizing and externalizing problem behavior in 12-year-old twins. Journal of the American Academy of Child and Adolescent Psychiatry, 42, $1351-1359$.

Bongers, I. L., Koot, H. M., Van der Ende, J., \& Verhulst, F. C. (2003). The normative development of child and adolescent problem behavior. Journal of Abnormal Psychology, 112, 179-192.

Brossard-Racine, M., Hall, N., Majnemer, A., Shevell, M. I., Law, M., Poulin, C., et al. (2012). Behavioural problems in school age children with cerebral palsy. European Journal of Paediatric Neurology, 16, 35-41.

Caspi, A., \& Shiner, R. L. (2006). Personality development. In W. R. M. Lerner, N. Eisenberg, \& W. Damon (Eds.), Handbook of Child Psychology. Vol. 3. Social, Emotional and Personality Development (6th ed., pp. 300-365). Hoboken, NJ: Wiley.

Colver, A. (2010). Why are children with cerebral palsy more likely to have emotional and behavioral difficulties? Developmental Medicine E` Child Neurology, 52, 986-986.

Costa, P. T., \& McCrae, R. R. (1992). Revised NEO personality inventory and five-factor inventory professional manual. Odessa, FL: Psychological Assessment Resources.

Cowan, P. A., \& Cowan, C. P. (2002). Interventions as tests of family systems theories: Marital and family relationships in children's development and psychopathology. Development and Psychopathology, 14, 731-759.

De Clercq, B., De Fruyt, F., \& Mervielde, I. (2003). Construction of the Dimensional Personality Symptom Item Pool in children (DIPSI). Unpublished Manuscript, Ghent University, Ghent.

De Clercq, B., De Fruyt, F., Van Leeuwen, K., \& Mervielde, I. (2006). The structure of maladaptive personality traits in childhood: A step toward an integrative developmental perspective for DSM-V. Journal of Abnormal Psychology, 115, 1-19.

De Clercq, B., De Fruyt, F., \& Widiger, T. A. (2009). Integrating a developmental perspective in dimensional models of personality disorders. Clinical Psychology Review, 29, 154-162.

Dekker, M. C., Nunn, R., \& Koot, H. M. (2002). Psychometric properties of the revised Developmental Behavior Checklist scales in Dutch children with intellectual disability. Journal of Intellectual Disability Research, 46, 61-75.

De Ruiter, K. P., Dekker, M. C., Verhulst, F. C., \& Koot, H. M. (2007). Developmental course of psychopathology in youths with and without intellectual disabilities. Journal of Child Psychology and Psychiatry, 48, 498-507.

Einfeld, S. L., \& Tonge, B. J. (1992). Manual for the Developmental Behaviour Checklist Primary Carer Version (DBC-P). School of Psychiatry, University of NSW, and Center for Developmental Psychiatry, Monash University.

Einfeld, S. L., \& Tonge, B. J. (1995). The Developmental Behavior Checklist: The development and validation of an instrument to assess behavioral and emotional disturbance in children and adolescents with mental retardation. Journal of Autism and Developmental Disorders, 25, 81-104.

Grietens, H., Onghena, P., Prinzie, P., Gadeyne, E., Van Assche, V., Ghesquière, P., \& Hellinckx, W. (2004). Comparison of mothers', fathers', and teachers' reports on problem behavior in 5- to 6-year-old children. Journal of Psychopathology and Behavioral Assessment, 26, 137-146.

Goodman, R. (1999). The extended version of the Strengths and Difficulties Questionnaire as a guide to child psychiatric caseness and consequent burden. Journal of Child Psychology and Psychiatry, 40, 791-801.

Hawker, D. S. J., \& Boulton, M. J. (2000). Twenty years' research on peer victimization and psychosocial maladjustment: A meta-analytic review of cross-sectional studies. Journal of Child Psychology and Psychiatry, 41, 441-455.

Hendriks, A. H. C., De Moor, J. M. H., Oud, J. H. L., Franken, W. M., \& Savelsberg, M. H. W. (2001). Behavior problems of young motor disabled children at home and in the therapeutic toddler class. European Journal of Special Needs Education, 16, 15-28.

Hinton, V. J., Nereo, N. E., Fee, R. J., \& Cyrulnik, S. E. (2006). Social behavior problems in boys with Duchenne muscular dystrophy. Developmental, and Behavioral Pediatrics, 27, 470-476.

Jenkins, J., Simpson, A., Dunn, J., Rasbash, J., \& O’Connor, T. G. (2005). Mutual influence of marital conflict and children's behavior problems: Shared and nonshared family risks. Child Development, 76, 24-39.

Jones, T. L., \& Prinz, R. J. (2005). Potential roles of parental self-efficacy in parent and child adjustment: A review. Clinical Psychology Review, 25, 341-363.

Ketelaar, M., Volman, M. J. M., Gorter, J. W., \& Vermeer, A. (2008). Stress in parents of children with cerebral palsy: What sources of stress are we talking about? Child: Care, Health and Development, 34, 825-829.

Koot, H. M., \& Dekker, M. C. (2001). Manual for the DBC (parent and teacher version). Rotterdam: Department Child and Adolescent Psychiatry, Erasmus Medical Centre, Sophia Children's Hospital/Erasmus University Rotterdam.

Koskentausta, T., \& Almqvist, F. (2004). Developmental Behavior Checklist (DBC) in the assessment of psychopathology in Finnish children with intellectual disability. Journal of Intellectual \& Developmental Disability, 29, 27-39.

Koskentausta, T., Iivanainen, M., \& Almqvist, F. (2004). CBCL in the assessment of psychopathology in Finnish children with intellectual disability. Research in Development Disabilities, 25, 341-354.

McDermott, S., Coker, A. L., Mani, S., Krishnaswami, S., Nagle, R. J., Barnett-Queen, L. L., et al. (1996). A population-based analysis of behavior problems in children with cerebral palsy. Journal of Pediatric Psychology, 21, 447-463.

Mitchell, D. B., \& Hauser-Cram, P. (2009). Early predictors of behavior problems: Two years after early intervention. Journal of Early Intervention, 32, 3-16.

Nigg, J. T. (2006). Temperament and developmental psychopathology. Journal of Child Psychology and Psychiatry, 47, 395-422.

O'Leary, S. G., \& Vidair, H. B. (2005). Marital adjustment, child-rearing disagreements, and overreactive parenting: Predicting child behavior problems. Journal of Family Psychology, 19, 208-216.

Palisano, R. J., Rosenbaum, P. L., Walter, S., Russell, D., Wood, E., \& Galuppi, B. (1997). Development and reliability of a system to classify gross motor function in children with cerebral palsy. Developmental Medicine and Child Neurology, 39, 214-233.

Parkes, J., White-Koning, M., O Dickinson, H., Thyen, U., Arnaud, C., Beckung, E., et al. (2008). Psychological problems in children with cerebral palsy: A crosssectional European study. Journal of Child Psychology and Psychiatry, 49, 405-413.

Peters, P. A. F., Huisman, J., \& Van Emmerik-Levelt, H. M. G. (1999). Gedragsproblemen en emotionele problemen bij kinderen in het Mytyl- en Tyltylonderwijs [Behavioral and emotional problems in children at schools for physically handicapped children and for multiply handicapped children]. Kind en Adolescent, 20, 44-51.

Prinzie, P., Onghena, P., Hellinckx, W., Grietens, H., Ghesquière, P., \& Colpin, H. (2003). The additive and interactive effects of parenting and children's personality on externalizing behavior. European Journal of Personality, 17, 95-117.

Prinzie, P., Van der Sluis, C. M., De Haan, A. D., \& Deković, M. (2010). The mediational role of parenting on the longitudinal relation between child personality and externalizing behavior. Journal of Personality, 78, 1301-1324.

Raina, P., O’Donnell, M., Rosenbaum, P., Brehaut, J., Walter, S. D., Russell, D., et al. (2005). The health and well-being of caregivers of children with cerebral palsy. Pediatrics, $115,626-636$.

Roberts, B. W., \& Caspi, A. (2003). The cumulative continuity model of personality development: Striking a balance between continuity and change in personality traits across the life course. In R. M. Staudinger \& U. Lindenberger (Eds.), Understanding human development: Lifespan psychology in exchange with other disciplines (pp. 183-214). Dordrecht: Kluwer Academic Publishers.

Rosenbaum, P., Paneth, N., Leviton, A., Goldstein, M., Bax, M., Damiano, D., et al. (2007). A report: The definition and classification of cerebral palsy April 2006. Developmental Medicine \& Child Neurology, 109, 8-14.

Sameroff, A. J. (1995). General systems theories and developmental psychopathology. In D. Cichetti \& D. J. Cohen (Eds.), Developmental psychopathology, Vol. 1: Theory and methods (pp. 659-695). New York: Wiley.

Saudino, K. J., Ronald, A., \& Plomin, R. (2005). The etiology of behavior problems in 7-year-old twins: Substantial genetic influence and negligible shared environmental influence for parent ratings and ratings by same and different teachers. Journal of Abnormal Child Psychology, 33, 113-130.

Schafer, J. L., \& Graham, J. W. (2002). Missing data: Our view of the state of the art. Psychological Methods, 7, $147-177$.

Shiner, R., \& Caspi, A. (2003). Personality differences in childhood and adolescence: Measurement, development, and consequences. Journal of Child Psychology and Psychiatry, 44, 2-32. 
Sigurdardottir, S., Indredavik, M. S., Eiriksdottir, A., Einarsdottir, K., Gudmundsson, H. S., \& Vik, T. (2010). Behavioral and emotional symptoms of preschool children with cerebral palsy: A population based study. Developmental Medicine E Child Neurology, 52, 1056-1061.

Sipal, R. F., Schuengel, C., Voorman, J. M., Van Eck, M., \& Becher, J. G. (2010). Course of behavior problems of children with cerebral palsy: The role of parental stress and support. Child: Care, Health and Development, 36, 74-84.

Sniekers, Grietens, S., \& Maes, H. (2002). Prevalentie van gedragsproblemen bij kinderen met een motorische handicap [Prevalence of behavior problems in children with a motor disability]. Tijdschrift voor Orthopedagogiek, Kinder-psychiatrie en Klinische Kinderpsychologie, 27, 162-175.

Tackett, J. L. (2006). Evaluating models of the personality-psychopathology relationship in children and adolescents. Clinical Psychology Review, 26, 584-599.

Van der Bruggen, C. O., Stams, G. J. J. M. , \& Bögels, S. M. (2008). Research review: The relation between child and parent anxiety and parental control: A metaanalytic review. Journal of Child Psychology and Psychiatry, 49, 1257-1269.

Van Handel, M., Swaab, H., de Vries, L. S., \& Jongmans, M. J. (2010). Behavioral outcome in children with a history of neonatal encephalopathy following perinatal asphyxia. Journal of Pediatric Psychology, 35, 286-295.

Van Leeuwen, K. G., Mervielde, I., Braet, C., \& Bosmans, G. (2004). Child personality and parental behavior as moderators of problem behavior: Variable- and person-centered approaches. Developmental Psychology, 40, 1029-1046.

Widiger, T. A. (2011). Personality and psychopathology. World Psychiatry, 10, 103-106.

Widiger, T. A., \& Mullins-Sweatt, S. N. (2009). Five-Factor Model of personality disorder: A proposal for DSM-V. Annual Review of Clinical Psychology, 5, 197-220.

Woolfson, L. (2004). Family well-being and disabled children: A psychosocial model of disability-related child behavior problems. British Journal of Health Psychology, 9, 1-13. 